\title{
Multimodal Modeling: Bridging Biosemiotics and Social Semiotics
}

\author{
Alin Olteanu ${ }^{1}$ (D) \\ Received: 16 July 2021 / Accepted: 27 October 2021 / Published online: 18 November 2021 \\ (c) The Author(s) 2021
}

\begin{abstract}
This paper explores a semiotic notion of body as starting point for bridging biosemiotic with social semiotic theory. The cornerstone of the argument is that the social semiotic criticism of the classic view of meaning as double articulation can support the criticism of language-centrism that lies at the foundation of biosemiotics. Besides the pragmatic epistemological advantages implicit in a theoretical synthesis, I argue that this brings a semiotic contribution to philosophy of mind broadly. Also, it contributes to overcoming the polemic in linguistics between, loosely put, cognitive universalism and cultural relativism. This possibility is revealed by the recent convergence of various semiotic theories towards a criticism of the classic notion of meaning as double articulation. In biosemiotics, the interest to explicate meaning as multiply articulated stems from the construal of Umwelt as relying on the variety of sense perception channels and semiotic systems that a species has at its disposal. Recently, social semiotics developed an unexplored interest for embodiment by starting from the other end, namely the consideration of the modal heterogeneity of meaning. To bridge these notions, I employ the cognitive semantic notion of embodiment and Mittelberg's cognitive semiotic notion of exbodiment. In light of these, I explore the possible intricacies between the biosemiotic notion of primary modeling system and concepts referring to preconceptual structures for knowledge organization stemming from cognitive linguistics. Further, Mittelberg's concept of exbodiment allows for a construal of meaning articulation as mediation between the exbodying and embodying directions of mind.
\end{abstract}

Keywords embodiment $\cdot$ exbodiment $\cdot$ containment $\cdot$ skin $\cdot \operatorname{cognition} \cdot$ mind

Alin Olteanu

alin.olteanu@rwth-aachen.de

1 Käte Hamburger Kolleg, RWTH Aachen University, Aachen, Germany 


\section{Introduction}

This paper aims to offer a starting point for bridging biosemiotic with social semiotic theory. The cornerstone of the argument is that the social semiotic criticism (Kress \& van Leeuwen, 2001) of the classic view of meaning as double articulation can support the criticism of language-centrism that lies at the foundation of biosemiotics (Sebeok, 1991). Besides the pragmatic epistemological advantages implicit in a theoretical synthesis, I argue that this brings a semiotic contribution to philosophy of mind broadly, by delivering a notion of mind not only as embodied but, following Mittelberg (Mitterlberg, 2006; Mittelberg, 2013), also as exbodied. In this view, body and mind, inner and outer, subject and object are not different phenomena but still distinguishable. It is revealing that, while making claims of anti-dualism, scholarship in biosemiotics persists to differentiate between construals of 'inner' and 'outer' as displayed by the notions of exosemiosis and endosemiosis (von Uexküll et al., 1983). To explore the semiotic notion of mind as simultaneously embodied and exbodied, I rely on Charles S. Peirce's notion of sign, as typical for biosemiotics. This notion, Deely (2001: 697) argued, allows for a view according to which "[t]he Innenwelt founds the Umwelt, but the Umwelt grounds the Innenwelt." In a cognitive scope, this means that, contrary to the common notion popularized by disembodied versions of semiotics, "[i]nference is perceptive" (Paolucci, 2020: 132). This is comprehended in Peirce's (CP 5.54) idea that facts are assessed in the form of perceptual judgments, namely, "asserting in propositional form what a character of a percept directly present to the mind is."

Biosemiotic theory has not been employed, so far, in conjunction with the recent multimodality framework (Kress \& van Leeuwen, 2001), developed in social semiotics. This is despite the common awareness that many animals model their environments multimodally (Martinelli, 2010: 91-93). The theoretical transformations in social semiotics entailed by this notion resulted in a framework that, I argue, can accommodate the biosemiotic notion of modeling (Sebeok, 2001; Sebeok \& Danesi, 2000), not without revising some entailed concepts (Olteanu et al., 2020; Campbell et al., 2021). Biosemiotics consists in a systems modeling theory, where modeling is conceived as "the innate ability to produce forms to stand for objects, events, feelings, actions, situations, and ideas perceived to have some meaning, purpose, or useful function" (Sebeok \& Danesi, 2000: 1). Simplifying, biosemiotics identifies meaning-making with the emergence of subjective environments. Because the "ability to make models is [...] a derivative of semiosis" (Sebeok \& Danesi, 2000: 5), a biosemiotic view implies construing and exploring multimodal meaning articulation as modeling. Actually, that modeling is multimodal is an underexplored implication of Sebeok's (1991) foundational idea for biosemiotics that language is not a primary modeling system. In agreement, Sonneson (1989: 291-300) argued that meaning-making processes that involve nonverbal (pictorial) features cannot be comprehended by an extrapolation of the notion of double articulation. Recent empirical biosemiotic research (Lancaster, 2014; Viana, 2017) links multimodality with a notion of 
symbol as reliant upon iconicity and indexicality, as stemming from Peirce. This echoes Jakobson's (1965) criticism of the arbitrariness hypothesis in linguisitcs, and Brandt's (2011) founding of cognitive semiotics, both relying on the Peircean differentiation and continuity of icon, index and symbol in representation. Another complementary but related justification consists in the recent effort to approach cultural phenomena from a distinctively biosemiotic perspective (Cobley, 2010, 2016; Olteanu, 2019; Rodríguez Higuera, 2018). Here, too, the biosemiotic notion of modeling is instrumental (Cobley, 2016: 28). My proposal is to bridge bio- and socio-semiotics via embodiment theory (e.g., Lakoff, 1987; Johnson, 1987; Varela et al., 2016). To this end, a semiotic concept of the body needs to be elaborated. The lack of a full-fledged biosemiotic theory of the body suggests the tremendous complexity of the task. The present paper makes only a modest contribution in this regard.

The development of a view on society as constructed through multimodal meaning-making (van Leeuwen, 2005; Kress, 2010) signals the intricacies of social semiotics with embodiment theory. To accept that meaning is multimodally articulated is to accept that meaning is designed through the entire panoply of available sense perception channels (Kress, 2010: 76). Despite Kress' observation, this affinity with biosemiotics has been overlooked so far. Also, the recent development of cognitive semiotics (Zlatev, 2015; Zlatev et al., 2016; Brandt, 2020; Paolucci, 2020), based on cognitive linguistics, reveals the epistemological need for bridging these theories. It is particularly in the scope of cognitive semiotics (Brandt, 2011) that the conflict between embodiment theory and the classic Saussurean (de Saussure, 1959 [1916]: 67-70) notion of the sign as linear and arbitrary has been observed. I mention that this paper does not aim to criticize or comment in any way on the authentic theory of Ferdinand de Saussure. I do not attempt a philological study of Saussure. Rather, the paper takes a critical position towards a certain legacy of Saussurean semiology, particularly as adopted in structuralism, regardless of Saussure's original considerations. This specific uptake of semiology is the target of criticism by, for instance, Hodge and Kress (1988), Stjernfelt (2007) and Brandt (2011). Also, it must not be overlooked that the reception of Saussure's linguistic theory has depended on Charles Bally and Albert Sechehaye's compiling of the celebrated Cours de linguistique générale (1967 [1916]).

Bio- and socio-semiotics did not develop an encompassing concept of the body, aside two starting points in the former, offered by Stjernfelt (2006) and Hoffmeyer (2008). This may be surprising in the case of biosemiotics, but it is due to the emphasis here on environment. Stjernfelt (2006) and Hoffmeyer (2008) indicate that a proper biosemiotic notion of the body eschews dualism. Explicating how the biosemiotic notion of environment (Umwelt) as model includes the body, as the origin of the emergence of modeling, in a way that still allows for a distinction between inner and outer, I argue, can serve as the connecting bridge. For this, I employ the mutual but complementary notions of embodiment and exbodiment. Embodiment theory developed distinctively in the cognitive sciences, which is essential to consider for the purpose of its uptake in semiotics. It makes two basic claims: "first, that cognition depends upon the kinds of experience that come from having a body with various sensorimotor capacities, and second, that these individual sensorimotor 
capacities are themselves embedded in a more encompassing biological, psychological, and cultural context" (Varela et al., 2016 [1991]: 173). This minimal definition by Varela et al. (2016) is general enough to be accepted by any approach to meaning as embodied, whether in agreement or not with these authors' notion of environment as enacted through the coupling of perception and action.

By explicating the notion of embodied mind in a semiotic terminology, recent cognitive semiotics reveals the path towards a more comprehensive theory within the panoply of semiotic schools. The mutual relevance between embodiment theory and biosemiotics is brought to the fore in Stjernfelt's (2006) approach to the body by paralleling idealized cognitive models (Lakoff, 1987) and primary modeling systems (Sebeok 1994, Sebeok, 2001). This observation underpins Stjernfelt's exploration of the intricacies for cognitive sciences of the semiotic notions of icon, particularly diagrams (Stjernfelt, 2007), and dicisigns (Stjernfelt, 2014). By observing the need for "a body concept which entails semiotics" (Stjernfelt, 2006: 14), Stjernfelt laid the premises for a synergy of biosemiotics and cognitive semantics. He (Stjernfelt, 2006: 14) points out that such a concept "makes evident the basic semiotic competences of an organism". Observing the affinities between Peirce's concept of icon and the cognitive semantic notion of schema, Stjernfelt (2014: 116, 203) deems the latter instrumental for developing "a diagrammatological linguistics", as it explains the continuity of meaning from preconceptual structures to prelinguistic concepts and to linguistic expressions. A central notion in cognitive semantics, image schemata are "embodied patterns of meaningfully organized experience (such as structures of bodily movements and perceptual interactions)" (Johnson, 1987: 19).

As coined by Peirce (EPII, 13; see Brandt, 2011: 51), icons are signs that mean because of similarity. The term iconicity, as well, was coined by Peirce (CP $4.561 n^{2}$ ), despite some confusion in scholarship (explained by Stjernfelt, 2015). Peirce regarded iconicity as the requirement that representations of logical operations must satisfy and as a principle that syntactically holds together a system of logical notations. It posits that a representation of an inference must be as similar as possible to the inference (EPII, 26). By considering that logic is spatial, Peirce was not alone in finding the visual modality particularly appropriate for logical notations. That we organize knowledge in terms of spatiality is, also, a founding argument in cognitive linguistics, particularly as elaborated in Langacker's (1987) cognitive grammar. An even more striking similarity with recent cognitive linguistics, remarked by Brandt (2011), is that Peirce also considered that both logic and, consequently, its representations are schematic. This means that inferences are not best performed through the manipulation of abstract symbols. Rather, logical quantifiers must share qualities with the concepts and operations for which they stand, so that some operations on the more accessible representation have the same conclusion (Interpretant) as they would have on the less accessible represented. The iconic relation entailed in the representation-represented-inference triad does not render the representation an absolute substitution for the represented. These two are similar pragmatically to the scope of the inference.

It is remarkable that, much earlier, Jakobson (1965) employed Peirce's theory of representation to undermine the dichotomy of signifier and signified, otherwise popular in structuralism at the time. Below I explore the implications for 
semiotic modeling of the CONTAINMENT basic image schema (Johnson, 1987). This reveals a new perspective on the mediation between endosemiosis and exosemiosis, Innenwelt and Umwelt. For this, I employ Mittelberg's concept of exbodiment, which posits that mind is "anchored in the concreteness of the human body, its physical habitat, and the intersubjective dynamics of communication" (Mittelberg, 2013: 757) because "the body portrays, i.e. exbodies, how the person [or organism $]^{1}$ conceptualizes and understands [...] abstracta." (Mittelberg, 2013: 776). This allows for construing the body as that which externalizes the mind, that which does the exbodying. At the same time, the body is also that which internalizes the mind, which does the embodying. As such, instead of discussing of body and mind, I propose exbodiment and, respectively, embodiment as instrumental terminology for biosemiotics. Moreover, the exbodiment notion invites reflection on the role of the body in social emergence, as it posits the body "as the locus where cognitivesemiotic processes take shape [...] thus providing anchorage for thought and theory in both physical surroundings and socio-cultural practices" (Mittelberg, 2008: 149).

\section{The Affinities of Bio-, Cognitive and Socio-Semiotics}

The biosemiotic view on meaning as modeling (Sebeok, 1991) resonates with the cognitive linguistic (Lakoff, 1987; Johnson, 1987) view on language as an embodied system for organizing experience and knowledge meaningfully. Cognitive semiotics starts with the presuppositions "that language is above all characterized by meaning, and that linguistic meaning is continuous with cognition and consciousness" (Zlatev, 2015: 1046). The first presupposition is specific to semiotics in general and implies that language has the role not only to communicate but also to produce and organize knowledge. Hence, language is a modeling system (Lotman, 1977, 1990; Sebeok, 1991). The second presupposition is specific to bio- and cognitive semiotics. Biosemiotics is founded on Sebeok's (1991: 56) assumption that linguistic and, implicitly, supra-linguistic (culture, art, science) modeling systems rest on a more basic, nonverbal modeling system. Sebeok based this theory on von Uexküll's (1926: 126) notion of environment as subjectively constructed through the organism's means of relating to its surroundings:

Every animal is a subject, which, in virtue of the structure peculiar to it, selects stimuli from the general influences of the outer world, and to these it responds in a certain way. These responses, in their turn, consist of certain effects on the outer world, and these again influence the stimuli. In this way there arises a self-contained periodic cycle, which we may call the function-circle of the animal.

By bringing this biological notion into the framework of Peirce's semiotics, Sebeok equated the environment with (semiotic) modeling: my environment is what I make sense of, the web of Interpretants of all semiosic processes I undergo. The

\footnotetext{
1 This is my addition.
} 
resulting theory implies that the primary, nonverbal modeling system cannot be bypassed by linguistic modeling because not only did the latter evolve as an adaptation based on the former but, also, because speech is an exaptation of language. This means that hominids have been capable to maintain language cross-generationally as a modeling system because of its utility in communication. Sebeok (1991: 56) explained that "language [...] itself came to be "exapted" for communication". With this observation, Sebeok aligned semiotics with the revolution that the progress of the natural sciences caused in the humanities, as remarkable in, among others, evolutionary anthropology (Gould, Vrba 1982; Lass, 1990), sociobiology (Wilson, 1998 [1975]; Alcock, 2001) and, of particular relevance here, cognitive semantics (Lakoff, 1987; Johnson, 1987). Sebeok's hypothesis that speech relies on nonve rbal meaning-making entails a semiotic and early theory of embodiment. Moreover, this view supposes a non-dichotomous construal of communication and modeling. Neither of these is strictly external or internal and they always proceed together. Most importantly, this implies that modeling and communication together drive the evolution of sign systems. Coming from a different perspective, this realization was also a foundation of Halliday's (1978: 10) notion of language as social semiotic:

[...] the ability to speak and understand arises and makes sense, only because there are other such organisms around and it is natural to think of it as an interorganism phenomenon to be studied from an inter-organism point of view. But it is also possible to investigate language from the standpoint of the internal make-up of that organism: the brain structure, and the cerebral processes that are involved in its speaking and understanding, and also in its learning to speak and to understand.

Later social semiotics tended to overlook Halliday's view on language as simultaneously inter- and intra-organism, focusing on the latter, which resemble the usual reception of Saussure. The view that language stems from the co-evolution of modeling and communicative competences supports that modeling systems that are cross-generational, such as culture, do not necessarily rely on linguistic (symbolic) modeling systems. Nevertheless, Halliday's systemic functional linguistics relies on de Saussure's theory throughout. This suggests that it might be possible to nest Saussure's semiology in an embodiment framework, different to its usual scholarly legacy $^{2}$. Aside but related to the scope of the present paper, exploring this aspect of Saussure's original theory in light of state-of-the-art cognitive linguistics could also be critical to overcoming the cognition/culture polarization in linguistics. Biosemiotics should not simply dismiss Saussure's semiology. Rather, exploring possible uptakes of his original theory might prove epistemologically more valuable.

\footnotetext{
2 Indeed, one of this paper's reviewers pointed to Tullio de Mauro's (Saussure 1973 [1916])) critical edition of the Cours de linguistique générale as a starting point for an embodied interpretation of semiology by accounting that Saussure's original notion of parole implies embodiment and situatedness.
} 


\section{Modeling}

Stjernfelt (2006) and Hoffmeyer (2008) offer two compatible starting points for a construal of the body as implied by the Umwelt notion. In Sebeok's (2001: 144) semiotic uptake of Uexküll's theoretical biology, while "subjective universe," "phenomenal world" and "self-world" are good candidates, Umwelt is best understood as "model".

Stjernfelt (2006: 14-15) remarks the compatibilities between, on the one hand, Peircean biosemiotics and, on the other, Merleau-Ponty's phenomenology of the body, cognitive semantics and the complexity theory of the Santa Fe school. He considers that these theories reveal not only an embodiment turn but an "embodiment semiotic turn" (Stjernfelt, 2006: 14). The courageous claim here is not merely that an embodiment turn is taking place in semiotics or that semiotics, too, rides the wave of the greater embodiment turn, but that the embodiment turn, such as exemplified in linguistics by the cognitive approach, has semiotic intricacies. Embodiment theory redirected the attention of linguistics, as well as of other areas of humanities, to semiotic questions. In the landmark Diagrammatology, published one year after this remark, Stjernfelt (2007: 53) layed this out even more clearly, identifying the embodiment turn not only with a semiotic and phenomenal turn, but also with an "iconic turn", claiming that "continuous models not reducible to algebra are introduced alongside feature-preserving mappings of such models between (mental) domains - in cognitive semantics, cognitive linguistics, in the Peirce renaissance in semiotics, etc."

Cognitive- and bio-semiotics evidence how the embodiment turn is an iconic turn. In brief, image schemata, force dynamics and, in general the embodied, prelinguistic and preconceptual patterns that cognitive semantics (e.g., Johnson, 1987) claims to structure experience meaningfully are icons, in the Peircean sense. Albeit with a different focus and in different terms, this is the starting point of biosemiotics. Sebeok founded biosemiotics by observing what is a Peircean criticism of semiotics as a cultural theory. It should be noted, at this point, that the icon concept must not be confused with (preconceptual) schema. Icon is not simply a semiotic counterpart of the cognitive image schema. Neither should either of these notions be confused with that of mental representation. Some mental representations can be considered icons, but, following Peirce, sign types are not bound to any specific modalities. Moreover, the Peircean notion of Representamen is not the same as mental representation, the latter being a specific notion in developmental psychology (Piaget, 2000 [1954]), later taken up in various incarnations in the wide panoply of cognitive sciences (see Morgan, 2014). In developmental psychology, the notion of (mental) representation relies on a different use of the schema term, understood not as preconceptual patterns for knowledge organization but as actual representations of concepts (see Paivio, 1990: 27). Confusion between Peircean Representamen and mental representation lies at the core of a mentalistic misinterpretation of Peirce, which resulted in representation theories overlooking Peirce's semiotics (as such examples see Ramsey, 2007, Morgan, 2014). Rather, mental representations are subcases of signs. 
Signs are not necessarily perceptive and/or cognitive (Hoffmeyer \& Stjernfelt, 2016). We only know, practically, semiosis as cognitive because of our specific embodiment. This does not mean, though, that all semiosis is cognitive. Icon is a semiotic concept of which image schemata are cognitive subcases. Both preconceptual structures and some more developed cognitive structures, such as mental representations, fall under the icon category. Of course, in cognition it is impossible to delineate a pure icon, as it is impossible to delineate any pure sign type. For instance, as a sign descriptive of quality, my impression of the blueness of the sky can be considered to come close to a pure icon, but my impression of the sky's color cannot be isolated from the rest of my experience, where many signs cooperate. The iconic turn in question here, mutual with the embodiment turn, does not involve the considerations of schema and mental representation as meant in Piaget's developmental psychology.

The various schools of semiotics, in the second half of the 20th Century, following de Saussure's notion of sign and construing meaning as double articulation, in a variety of incarnations (Martinet 1962, Hjelmslev 1954), had sedimented strongly anthropocentric and language-centered theories of language and culture. For his theory of meaning as co-extensive with life, Sebeok found useful Lotman's (1977, 1990) view of semiotic systems as modeling systems, illustrative for the Tartu-Moscow school. In this conception, natural language is a modeling system which allows for the further development of more complex and abstract, second order modeling systems, such as culture. In light of Uexküll's biology, Sebeok adopted the idea of semiotic modeling systems with the critical amendment that language is not the primary system. The primary modeling system of humans is located where the primary modeling system of any organism is located, proceeds Sebeok's (2001: 148-149) argument, namely in the non-linguistic, schematic structures generated by a body's relation to its environment:

[...] the relatively simple, nonverbal models that animals live by and that normal human infants likewise employ are more or less pliable representations which, as we saw, must fit 'reality' sufficiently to tend to secure their survival in their ecological niche (an ethological expression which, in semiotic parlance, refers to the Umwelt as viewed by an observer of the subject under scrutiny).

Like image schemata in cognitive semantics, the nonverbal models described by Sebeok are "pliable representations". That the cognitive notion of image schema belongs to primary modeling is exhibited by Ureña Gómez-Moreno's $(2014,2019)$ recent studies on semiosis in the mimic octopus and the Gibb's sea spider crab. Biosemiotics and cognitive semantics agree that the rationale of language is to organize knowledge, more than merely communicating it to other organisms. This supports that, at least for social species, behavior cannot be explained simply as individual or social. Because organisms communicate by means of modeling systems, modeling systems develop both through introspection and intra-organism communication. In agreement with the Tartu-Moscow school in this regard, Sebeok saw natural languages to support the development of culture, art and other such superstructures, but which he deemed tertiary modeling systems. 
There is disagreement between Sebeok's biosemiotics and Lakoff's cognitive semantics regarding the idea that models fit a reality external to them (Sebeok, 2001: 148). While observing some merits of Gibson's affordance theory (Gibson, 1979), Lakoff (1987: 215-216) criticized this approach to perception because of a supposed objectivism. Lakoff took issue with Gibson's distinction between environment, as constructed by an organism, and landscape, as the physical setting in which a species' perceptive senses evolved. Lakoff's position, though, risks subjectivism: if landscape does not limit meaning-making, is meaning-making not entirely arbitrary? As Sebeok's wording suggests, Gibson's affordance theory easily found its place in the framework of biosemiotics: meaning has to fit factuality. From a biosemiotic perspective, Campbell et al. (2019: 367) construe "affordances as potential semiotic resources", taking the latter concept from social semiotics (van Leeuwen, 2005). Following Gibson's theory of perception, van Leeuwen (van Leeuwen, 2005: 4-5) avoids Saussurean arbitrariness by arguing that sign systems provide resources that have semiotic potential rather than consisting in fixed form-content articulations. From this perspective, there is affordance between forms and meanings. In this light, Campbell et al. (2019: 359) define "semiotic competence as the capability of an organism, dependent on its embodied morphology, to discover meaning resources in a given environment and to recombine them in new, pragmatically functional models. As such, semiotic competences are employed to scaffold knowledge, which is to say, to develop models of (aspects of) their environment, which result in a capacity to navigate in the environment." Semiotic scaffolding was defined by Hoffmeyer (2015: 154) as "what makes history matter to an organism (or a cultural system)". This concept implies that Umwelten are gradually constructed, as meanings get to support more complex meanings in the organization of knowledge. It serves to argue that nature "is not so much about "tooth and claw" as it is about sensing, interpreting, coordinating and social co-operation" (Hoffmeyer, 2015: 154). This allows for the analysis of culture as gradually constructed through "the piecing together of the semi-autonomous parts of a scaffolding", which have "the character of meaning-bearing couplings as they support still more complicated versions of the basically significant perception-action cycle" (Cobley \& Stjernfelt, 2015: 292).

\section{Multimodal Environments}

The assumption in cognitive semantics and biosemiotics that language relies on nonlinguistic and schematic structures implies that meaning-making is multimodal. If a more basic sign system supports the articulation of linguistic signs, then linguistic signs find resources and, hence, a part of their motivation therein. While cognitive semiotics plentifully discusses the notion of multimodality (Zlatev et al., 2017), which it also distinguishes from polysemiotic representation as referring to the articulation of signs coming from different systems, regardless of sense perception channel (Zlatev, 2019), it is seldomly considerate of the full-fledged multimodality framework in social semiotics.

Attempts to bridge bio- and socio-semiotics lack altogether, despite some obvious overlaps and compatibility. Social semiotic analyses of cultural artefacts often tend 
to overlook that Halliday's (1978: 1) foundational notion of language as semiotic rests on a notion of environment as simultaneously social and physical:

The 'environment' is social as well as physical, and a state of wellbeing, which depends on harmony with the environment, demands harmony of both kinds.

Halliday formulated his semiotic project as an answer to one-sided physicalist attempts to tackle human wellbeing, as displayed by early enthusiasm for ergonomics. He acknowledged the role of physicality and materiality in the design of human environments, implying that form is meaningfully perceived in cultural environments, even if there is no conventional meaning assigned to it. In this notion lies the seed of the multimodality framework, which social semiotics eventually arrived at. The construal of meaning as embodied contradicts the traditional view that semiotic systems, such as language, can be monomodal. That the modeling work of language proceeds as afforded by human embodiment means that language operates upon multimodal structures (Mittelberg, 2013, 2019), albeit through the mediation of the cognitively simpler halfway house of pantomime (see Zlatev et al., 2017).

The need for a comprehensive and integrated semiotic theory resides in simultaneously understanding the social and biological dimensions of semiotic systems. In this regard, biosemiotics can provide useful notions. Biosemiotics relies on the semiotics of Charles S. Peirce (Favareau, 2010: 38-39, Rodríguez Higuera, 2019), starting with whom, arguably, semiotics displayed a program, however covert at times, of undermining mind/body dualism. Following Umberto Eco, Paolucci (2020: 2) holds that Peirce's theory is a "cognitive semiotics", in a loose sense, and that "a theory of cognition without semiotics" is not possible.

\section{Subject-Object}

Peirce's semiotic logic, by its central notion of sign as triadic, eschews the subject/ object dichotomy (Sebeok, 2001: 34) supposed by Immanuel Kant's transcendental idealism. Emphasizing this rationale of Peirce's semiotics, Deely (2001) termed the Peircean sign "suprasubjective". Peirce regarded meaning-making as semiosis (EPII, 411), the simultaneous cooperation of three termini: a Representamen, which represents an Object in such a way that brings forth an Interpretant (conclusion of interpretation). These three elements of semiosis are interdependent in a triadic manner. The Object, while distinguishable, is not contrasted to a Subject. The three elements of the sign correspond to three categories that Peirce considered manifest in meaning (EPI, 247-250). His conceptualization of meaning as relying on categories (EPI, 362) populated by qualities governed by chance (Firstness), objects governed by necessity (Secondness) and universals governed by selfless love (agapism, Thirdness) was criticized by some as a priorism (Koopman, 2009). However, other scholars, particularly in a semiotic scope, argue that Peirce's pragmati(ci) sm does not posit (any of) these categories as ontologically a priori. Rather, they are manifest in a mingled way, in their simultaneous cooperation in signs (Merrell, 2001; Mittelberg, 2019; Olteanu, 2019). Peirce explained that not even in imagination can the categories be dissociated one from the other (CP 1.353). Rather, he 
argued that the categories and, hence, the termini of the sign, can be prescinded from reality. The prescinded termini do not necessarily mirror the phenomenality of semiosis which organisms undergo. For instance, Peirce exemplified prescission by our capacity to "suppose uncolored space, though we cannot dissociate space from color" (CP 1.353). While the method of prescission is important for (human) modeling it is also highly abstract: colored space is experienced in the concrete form of perceptual judgements before the abstract ideas of uncolored space or formless color can be inferred.

Sebeok $(1965,1991: 17)$ construed meaning as co-extensive with biological life by relying on Peirce's semiotics as an appropriate framework for eschewing dualism. This modeling theory, I argue, can be further developed by explicating its intricacies for a notion of the body that is compatible with recent notions in cognitive semiotics. This allows understanding the organism-environment relation as continuous while not confusing the inner organism and its outer environment. Further, it implies construing the experiencing of subject and object as continuous within one phenomenon (a perceptual judgement), while not confusing them. This distinction avoids the objectivist claim that "[s]ymbols that correspond to the external world are internal representations of external reality" (Lakoff, 1987: xiii). Rather, it acknowledges that CONTAINMENT, as a main characteristic of existing as an individually embodied organism, implies a "physical in-out orientation" in the organization of knowledge, which "involves separation, differentiation, and enclosure, which implies restriction and limitation" (Johnson, 1987: 22).

\section{The Environment in The Body}

In the biosemiotic conception, following Uexküll (1926), environments are modelled by organisms, which exert their semiotic competences (Nöth, 1998; Maran, 2020: 5-7). That is, through their competences to discover meaning, organisms shape environments. Semiotic competences stem from the body and its relation to its surroundings. Body, mind and environment are not confused, but neither contrasted with each other. The body is in the mind, as Johnson (1987) resoundingly claimed. The mind constructs an environment but it does so not out of nothing. It works with the relations that it can gradually conceive in its setting, which are semiotic resources, employed to scaffold new meanings (Campbell et al., 2019). Hence, as a distinction can be observed between the body in a strict physicalist sense and its external extensions, I propose blurring the mind/body dichotomy while still maintaining a conceptually useful distinction. Instead of this misleading dichotomy, I propose a complementarity between embodiment (Lakoff \& Johnson, 1999) and exbodiment (Mittelberg, 2013), as two directions manifested by a mind. Here, I illustrate the relevance of this notion of mind by discussing its intricacies with the CONTAIMENT basic image schema (Johnson, 1987). The biosemiotic construal of the skin organ (Hoffmeyer, 2008) is employed to explain the phenomenality of the self as contained by a permeable membrane. This challenges semiotic construals of boundary and opposition in general. Following Peirce's method, the embodied and exbodied mind can be prescinded from the full semiotic phenomenality of the body. 
A basic tenet of cognitive linguistics is that organisms make sense of experience through recurring patterns that stem from bodily movements and perceptual interactions with(in) the environment. Adopting Kant's use of the term, cognitive linguistics and its entailed philosophy of embodiment refer to these patterns as schemata. Johnson (1987: 29) describes schema as "a continuous structure of an organizing activity", consisting in, like the Peircean notion of diagram (EPII, 274), "parts and relations, by virtue of which it can structure infinitely many perceptions, images and events" (1987: 29) Containment is one of the most basic schemata by which organisms organize experience meaningfully. Johnson (1987: 21) explains:

Our encounter with containment and boundedness is one of the most pervasive features of our bodily experience. We are intimately aware of our bodies as three-dimensional containers into which we put certain things (food, water, air) and out of which other things emerge (food and water wastes, air, blood, etc.). From the beginning, we experience constant physical containment of our surroundings (those things that envelop us).

\section{Contained in Skin}

From a biosemiotic perspective, too, it can be argued that containment is a basic principle for organizing experience into knowledge. To begin with, this is suggested by von Uexküll's (1926) construal of the functional-circle of an organism as "self-contained".

Hoffmeyer (2008) argued that not only the (human) self but even personality is contained within skin. Dualist philosophy regards the skin as a boundary. According to Hoffmeyer (2008: 173), the skin has a double role:

On one hand, the skin thus serves us as a kind of topological boundary; while, on the other hand, its semiotic capacity opens up the world to us-so that the question of where our 'self' begins and ends is not at all an easy question to answer scientifically.

Hoffmeyer's proposal that personhood is located in the skin may appear controversial given both the dualist confusion of mind and the brain organ and the cognitive semantic view that mind is evoked by the entire body (Lakoff \& Johnson, 1999). However, a proper cognitive and bio-semiotic approach finds interest, first of all, in the locus of transition, of mediation. In-out orientation schemata are justified by "seeing the world "from the skin's perspective"" (Hoffmeyer, 2008: 172). Because "skin has both an inner side and an outer side and an asymmetry is therefore established by the skin between that which is inside and that which is outside" (Hoffmeyer, 2008: 174), the skin is the locus of mediation, where semiosis encompasses both embodied and exbodied cognitive processes.

In this conception, inner and outer are not conceived as phenomenally distinct. This distinction is only implied by the objectivist supposition that on one side of the skin arbitrary signs (pure symbols) correspond to entities from the other side of the skin. From this point of view, criticised as objectivism (Lakoff, 1987), the outer 
world is navigated by a reason that operates only on its internally conceived signs and can merely suppose 'external things'. Following Brandt (2011, below), my argument is that the biosemiotic notion of skin allows a construal of thinking as iconic mediation between inner and outer. Instead of isolating the self as an ontologically secluded consciousness in a world that is essentially alien to the self, like a wall would, the skin is permeated by iconic semiosis. Semiotically, the self belongs in the world. As such, while the "present moment of a human being is [...] in itself a representation" (Brandt, 2011: 54), the self is not a sum of inner representations of external entities. Rather, it is a hermeneutic circle (Nöth, 1998), comprising of Umwelt and Innenwelt at once.

Organizing experience mentally in light of containment implies not only that the mind is embodied but that, simultaneously, it is also exbodied (Mittelberg, 2013). These two directions implied by containment reflect the Uexküllean notions of Innenwelt and Umwelt (Uexküll 1926: 126-128), respectively. Mittelberg observes the exbodied mind in communicative bodily gestures. She explains that "[e]xbodiment entails the motivated semiotic structure inherent to communicative gestures made with the hands and arms, as well as to expressive postures and full body movements" (Mittelberg, 2013: 756). The exbodied mind is not manifest only occasionally, in deliberate nonverbal communication. Rather, it is the condition of organisms' environmental situatedness. Exbodiment was observed in nonverbal communication because "gestures are particularly good examples of the spontaneous exbodiment of conceptual structure" (Mittelberg, 2013: 770). Mittelberg explains that gestures are intrinsic to thought, as the shaping of gesture can literally coincide with the shaping of schemata or concepts. This does not mean that gestures are not the only means of exbodying. Speech, as well, may be a form of exbodying. Mediatizations of conceptual structure between the inner and outer sides of containment serve as semiotic scaffoldings for further modeling. Gestures partake into the explaining of ideas both to others and to the self and are, as such, mediated mind work, following Elleström (2018). Simply put, I understand myself and mediate myself to others through my body.

Exbodiment is the cognitive correspondent to the semiotic Umwelt. Herein occurs how biosemiotics, in light of decades of conceptual work on notions of environment, can contribute to cognitive linguistics. The embodied mind contains "preconceptual bodily experiences" (Lakoff, 1987: 267), which structure more complex and abstract concepts, also in linguistic form. In the modeling-centered view of biosemiotics, these bodily experiences roughly translate as Innenwelt:

The Innenwelt of every animal comprises a model [...] that is made up of an elementary array of several types of nonverbal signs [...]. (Sebeok, 2001: 145)

Embodiment and exbodiment constitute one mind, not two. It is the same mind that evokes (and is invoked by) embodiment and exbodiment. The key towards the synthesis of biosemiotic and social semiotic theories lies in a construal of mind according to which the relation between exbodiment and embodiment is iconic, in the Peircean sense. From this perspective, the wholeness of a consciousness that constitutes a mind is assured by the continuous flow of meaning (semiosis) across Innenwelt and Umwelt. From this perspective, thinking is a multimodal translation, 
as I also argued in a social semiotic scope (Olteanu, 2020). Biosemiotic and cognitive semiotic theories offer an additional and more refined explanation of thought as inner translation between either present and future Umwelten, present and future Innenwelten or Innenwelt and Umwelt. Sebeok (2001) also noted that his modeling theory implies that "the message-as-formulated must undergo a transductive operation to be externalized into serial strings appropriate to the channel, or channels, selected to link up with the destination." Such mediatization of meaning is here construed as exbodying.

That thinking is translating corresponds to Peirce's foundational claim for semiotics that "thinking always proceeds in the form of a dialogue [...] between different phases of the ego [...] so that, being dialogical, it is essentially composed of signs" (CP 4.6). In this regard, Peirce's concept of thought is remarkably similar to Bakhtin's (2008) notions of internal dialogism and heteroglossia, which were eagerly adopted not only in sociolinguistics, but also in social semiotics (Hodge, Kress 1988: 14; Kress, 2010: 73). In brief, the study of linguistic variation as intrinsic to the linguistic phenomenon implies construing thought as dialogical. While dialogical thought can occur between a present and future Innenwelt, my argument is that it also occurs between Innenwelt and Umwelt, through the skin. Actually, thought can only be dialogical because the mediation between Innenwelt and Umwelt is iconic: qualities of meaning-bearing features are preserved from one to the other.

At least in the case of humans, the basic semiotic competence that secures the continuity of meaning between (or within) the embodied and exbodied mind is imagination which, in a Peircean view, is preponderantly iconic (Pietarinen \& Bellucci, 2016). As evidence for the iconicity of imagination, Stjernfelt (2007: 81) remarks that logical inconsistencies (e.g., 'round square') cannot be imagined. Herein lies a little explored compatibility between contemporary cognitive linguistics and Peirce's semiotics. First, imagination is deemed as essential for knowing and, second, it is construed as broadly schematic. Iconicity is Peirce's concept of 'schematicity', on which he founded his system of graphic notations for logic (Stjernfelt, 2015; CP $4.561 \mathrm{n}^{2}$ ). It refers to "the sign-relation making one phenomenon signify another by similarity in some respects." (Stjernfelt, 2007: 49) Particularly, diagrams, which are the specific type of icons where similarity is manifest in part-whole relations, are Peirce's equivalent to the Kantian schema (Stjernfelt, 2007: 89; Paolucci, 2020: 132; Pietarinen \& Bellucci, 2016: 472), albeit free of subject/object dualism. From this perspective, the relation between the embodied and exbodied mind is diagrammatic, as these two are parts of the same whole.

\section{Culture or Cognition: the Saussurean Split}

The efforts to anchor reason in the (human) body in cognitive linguistics and semiotics are reactant to the mainstream linguistics of the 20th century, which can be regarded as a spin-off of Cartesian dualism. Transcendental idealism was only in part rejected by the linguistic turn (Rorty, 1992 [1967]), namely the switch of focus from mental ideas to language as the main vehicle of epistemology. While nevertheless advocating that reason operates with subjective meaning rather than objective 
ideas, the linguistic turn reiterated rather than undermined mind/body dualism. The linguistic turn is rooted in Ferdinand de Saussure's semiologie, the study of "the life of signs in society" (de Saussure, 1959 [1916]: 16), where the notion of sign is based on the subject/object dichotomic distinction. Saussure (de Saussure, 1959 [1916]: 67) defined the sign as a "two-sided psychological entity", one side consisting in (perceived) form and the other in (mental) content. Saussure (de Saussure, 1959: 67) termed the former signifier (signifiant) and the latter signified (signifié), establishing the terminology that eventually marked the split between a cognitive and a social focus in linguistics. This dichotomized notion of sign exhibits the modern distinction between subject and object, which it takes in a linguistic dimension. Jakobson (1965) criticized this dichotomy in linguistics early on, when structuralism manifested a strong enthusiasm for the idea of opposition as a tool for analysis. A common and influential reception of semiology in cultural studies relies on the assumption that the articulation of a signifier and a signified into a sign is possible and functional because of the fundamentally arbitrary relation between the former two. The arbitrariness of the sign is crucial, from the (post-)Saussurean perspective, because it assures the immutability of language as a social phenomenon. By insisting that "language is a social fact" (1959: 6), Saussure also meant that language is never individual. This suggested, though, that only speech is individual and different manners of speaking do not account for language variation. The underpinning argument is that because language functions only in virtue of social convention it is best established upon pure arbitrariness: if the signifier would suggest the signified, the semiotic system would not be properly social. If that were the case, individuals could corrupt language, which, by deviating from collective immutable conventionality, would lose its social use. Also, if the articulation of the sign would display a motivation that can be intuitively grasped, at least in part, by outsiders of the semiotic system, the system's wobbly boundaries would unavoidably lead to its dissolvement. From this perspective, a language must have clear and fixed boundaries. Arbitrariness guarantees that. Starting with Labov's (1972) studies on the logic of non-standard language, foundational for sociolinguistics, the concept of linguistic immutability has been seriously challenged. Instead of being immutable, the linguistic phenomenon is characterized by variation intrinsically. As such, the Peircean notions of token and type can more accurately describe how linguistic reference works, while no Representamina are identical, and how languages (and any sign systems in general) change through the reiteration of similar (not identical) Representamina.

The Saussurean dichotomy of speech and language, implied from that of signifier and signified, resulted in a split between what have been a cognitive and social focus in linguistics. The former tends to regard language as an innate mental capacity of humans and the latter dismisses the biological apparatus that makes language possible (Geeraerts \& Cuykens, 2007: 11):

The $[. .$.$] decontextualization of twentieth-century grammar may be grasped$ if we take our starting point in Saussure. The Saussurean dichotomy between langue and parole creates an internally divided grammar, a conception of language with, so to speak, a hole in the middle. On the one hand, langue is 
defined as a social system, a set of collective conventions, a common code shared by a community [(de Saussure, 1959)]. On the other hand, parole is an individual, psychological activity that consists of producing specific combinations from the elements that are present in the code [...]. When langue and parole are defined in this way, there is a gap between both: what is the mediating factor that bridges the distance between the social and the psychological, between the community and the individual, between the system and the application of the system, between the code and the actual use of the code?

The two sides of the split exhibit biologism, the claim that human behavior and social organization are biologically determined, and, respectively, culturalism, namely that the behavior of human individuals is determined by a culture to which they belong. In a recent development of a semiotic framework for observing wildlife, Eliott (2019: 20) explains the pitfalls of both of these positions:

Those who eschew causation tout court, or who reject empirical research or indeed scientific realism without further ado, run the risk of relativism, idealism, or what is equally problematic, a rampant culturalism. As the cultural critic Terry Eagleton puts it, culturalism is the doctrine that everything in human affairs is a matter of culture [(Eagleton, 2000: 91)]. Culturalism is the obvers of biologism, the stance adopted by those who attempt to reduce everything in human affairs to a transcendental biology. Culturalism is no better than biologism; on the contrary, when culturalism takes over, then it becomes rather difficult to explain why academics' bodies (as distinct from some of their/our theories) don't simply float away.

In an effort to overcome dualism, structuralism and the linguistic turn only managed to foster culturalism, as a form of linguistic rationalism and biologism, as a form of linguistic empiricism. The latter is manifest, for instance, in theories that construe language as computational, as a software of the human mind, such as Chomsky's generative grammar. The former is manifest in a broad spectrum of the humanities, from early American anthropology (e.g., Boas 1911, Benedict, 1934), to discourse theories (Barthes, 1977; Foucault, 1981). While sociolinguistics (Bernstein, 1960; Labov, 1972) loosened the polarization between language and speech, marking a critically important progress in this brand of approach to language, it remains distinct from cognitive approaches. In their most rigid forms, linguistic rationalism considers that language is individual and internal, its rationale being to categorize entities of experience, and linguistic empiricism considers that language is social and external, meant for inter-personal communication only. In a retrospective outlook, Geeraerts and Cuykens (2007: 13-14) explain that Cognitive Linguistics, as distinct from earlier attempts to conceptualize language as a characteristic cognitive capacity of the human brain, developed because of the need to bridge these two polarizing traditions of linguistics.

Pondering on the prospect of a cognitive semiotics, more specific but of more encompassing scope than cognitive linguistics, Brandt (2011: 50) notes that the concept of sign marks "a sort of phenomenal 'wall' isolating the signifier's proximal locus and the signified's distal locus". Certainly, Brandt is here 
pointing to the heritage of Saussurean semiology. This concept of sign is functional, Brandt explains, because of its evidencing of the distinction between the signifying phenomenon and the signified phenomenon. However, Brandt observes that a particularity of the cognitive semiotic project consists in understanding the relation between signifier and signified, metaphorically, not as dividing wall but as connecting window. He (2011: 50-51) concludes that this implies replacing Saussure's arbitrariness with iconicity as the principle that makes language operational:

The principle of semio-phenomenal wall invites a strikingly accurate analogy, or instantiation, namely a building with an interior and an exterior. The windows show to people situated in the interior what is happening in the exterior part of the space: windows show icons of the exterior to the observers located in the interior. Icons are windows, we could say metaphorically

(A IS B, in G. Lakoff's conceptual metaphor format).

This project is not new but, rather, delayed. According to Jakobson (1965), the essence of language resides not in arbitrariness, as the characteristic relation between signifier and signified, which renders language a social convention. Instead, Jakobson drew on Peirce's semiotic terminology to explain that language is operational because of its diagrammatic structure. This is to say that language functions in virtue of an internal iconic syntax. Jakobson (1965: 23-24) noted that Peirce's division of representation into icons, indexes and symbols rests on the supposition of an isomorphism between form and content (signans and signatum), which is displayed in the Interpretant. The continuity of this trichotomy of representation is manifest in language, meaning that the symbols of language rely upon indexes which, in turn, rely upon icons. My argument is that what Brandt's semio-phenomenal windows are mediating are the embodied and exbodied mind. The entailed "diagrammatological linguistics" can serve to bridge bio- and social semiotics. This view on language is intrinsic to Hoffmeyer's (2008) biosemiotic notion of the body. The animal's semio-phenomenal window, through which an iconic isomorphism between inner and outer is established, is the skin.

In laying the foundations of social semiotics, Hodge and Kress (1988) echoed Jakobson (1965) and aimed to bridge the same gap that Geeraerts and Cuykens (2007) later noted. Namely, they (1988: 15) adopted the Saussurean idea of semiology while criticizing its clear-cut distinctions between form and content, speech and language and, in general, its insistence upon opposition as instrumental for the potential of sign systems to establish reference:

On the one hand [Saussure] projected a discipline with the widest possible scope, while on the other he laid down a set of strictures which split his heritage in two, deforming linguistics, and preventing the coming of semiotics for decades.

While Jakobson focused on language, Hodge and Kress (1988: 16) also addressed the broader consequences of semiology for cultural studies: 
The Saussurean scalpel cut deep, and his need for limits has found echoes in many others who have set up sterile barriers, in linguistics and in many other fields of cultural studies.

While recognizing the merit of Peirce's semiotics to avoid such polarization, Hodge and Kress (1988: 20) nevertheless explicitly criticized Peirce, too, in a manner that has been persisting in this line of scholarship:

C.S. Peirce [...] had a dialogic conception of language and signs. [...] Unlike Voloshinov, he has internalized the transaction that constitutes thought, presenting it as a fact of personal psychology without explicit roots in the social process, and this is an important weakness in Peirce's theory.

This criticism of Peirce, rather common throughout the second half of the 20th Century, is misplaced. While the Peircean notion of sign is not bound to one specific modality, easily accommodating contemporary views on multimodality, social semiotics has been avoiding it. In this regard, the uptake of Peirce in biosemiotics and cognitive semiotics can lead the way to a concept of the body acceptable for social semiotics, too. Contrary to Hodge and Kress' criticism, the reason for which Peirce was not concerned with the social and cultural dimension of signs is intricate to that for which he was, actually, not concerned with their psychological dimension either. Peirce found interest in the notion of sign, the transaction (or substitution) to which Hodge and Kress referred, because of its instrumentality in elaborating an anti-psychologistic logic (Stjernfelt, 2014; see Olteanu et al., 2020; Campbell et al., 2021). Peirce did not ascribe the action of signs to personal psychology or social cognition. This is one of the main reasons for which the concept has been essential for biosemiotics. The argument is that the Peircean notion of meaning-making as semiosis does not confuse meaning and perception, the latter being "the process of creating internal models of events or things in the surroundings" (Hoffmeyer \& Stjernfelt, 2016: 9). Perception, not to mention cognition, relies on semiosis, not the other way around, requiring rather complex biology. The immune and nervous systems of organisms, from this perspective, are proper semiotic systems, which "make the body recognize and respond to whatever situation it happens to meet. Or, to put it differently, these endosemiotic tools are collectively responsible for the interaction of the organism with its social and physical world and constitute the fundament out of which so-called psychological reality, if any, of the organism will emerge" (Hoffmeyer \& Stjernfelt, 2016: 9). This uptake of the Peircean notions of sign and semiosis in biosemiotics avoids the Saussurean scalpel, as well as implied culturalism and biologism.

Hodge and Kress were not the only major authors to miss the anti-psychologism of Peirce's semiotics at the time. While they observed Saussure's semiology to generate a split in research on meaning, they nevertheless took the side of culturalism and subjectivism, painting a view of Peirce's semiotics as belonging to the computational and objectivist brand. Their cultural criticism (1988:2-3) still endorsed the language-centrism of the linguistic turn, revolving around a deconstruction of ideology as "logonomic system". The more recent elaborations in biosemiotics, as illustrated by Hoffmeyer and Stjernfelt (2016), render Peirce's semiotics rather 
acceptable for Hodge and Kress' project in a way that, if followed, would also avoid culturalism and language-centrism. Hodge and Kress' early social semiotics did not arrive at a complete detachment from the dichotomic notion of the sign and its culturalist implications. It is rather its more recent development into the multimodality framework (Kress \& van Leeuwen, 2001: 4), which fundamentally is a criticism of the Saussurean split:

Where traditional linguistics had defined language as a system that worked through double articulation, where a message was an articulation as a form and as a meaning, we see multimodal texts as making meaning in multiple articulations.

This criticism of monomdality as relying on the notion of double articulation, in the most general sense, can be bridged with what has been termed (Rodríguez Higuera, 2019) post-Peircean biosemiotics. The iconic logic of Peirce's semiotics started to enjoy more attention recently, particularly in light of the emergence of cognitive linguistics and the important role in meaning-making that this approach attributes to simple, prelinguistic meaning structures, such as expressed by the notion of schema (Stjernfelt, 2007). The criticism to symbolic calculus herein, namely that "the mere substitution for some objects or object categories by letters or the like makes no manipulable icon" (Stjernfelt, 2007: 79) is aligned with Lakoff (1987) and Johnson's (1987) criticism of objectivism. Objectivism is the version of transcendental philosophy, popularized by positivism, claiming that to distinct entities in the world, distinct mental concepts correspond and that the representation of these concepts in the form of abstract symbols makes an operational system of (logical) notations.

\section{Conclusions}

The view that language develops as evoked and constrained by schematic structures of meaning that emerge from the body's relation and interactions with(in) its environment is not compatible with the Saussurean signifier/signified dichotomy, at least in its uptake in (post)structuralism and alongside the linguistic turn. As much as it may rely on conventions, language is motivated by prelinguistic structures of meaning. As Brandt (2011: 50) explains, "the semiotic function works across the "wall'". Iconicity accounts for a window-like connection in the articulation of form and content into signs. This connection implies a dialectic of the two, leading to a notion of meaning as multiply articulated design, as proposed by the social semiotic multimodality framework (Kress \& van Leeuwen, 2001).

The key notion that allows integrating the biological and socio-cultural approaches to language, eschewing transcendental idealism stands in the mediation of embodiment and exbodiment. My argument is based on the observation that the biosemiotic concept of environment as model (Sebeok, 1991) is intricate of a view of meaning as embodied. Uexküll's (von Uexküll, 1926) concept of Umwelt construes the body as part of the environment, not its distinct, passive observer. This view also lies at the foundation of ecosemiotics. As proposed by Nöth (1998: 339), 
the biosemiotic approach to ecology relies on a cognitive implication of the Umwelt notion: instead of supposing a correspondence between mind-dependent (inner) and mind-independent (outer) entities, in a dualist fashion, organisms display an internal-external complementarity through their modeling:

The meanings and signs of [...] Umwelt are by no means transmitted from an exterior environment to the interior of an organism. Instead, there is a relation of complementarity between the Umwelt and the inner world of the organism. The carrier of meaning has the function of a "counter-structure" of the receiver of meaning [...]. Umwelt and inner world thus constitutes a hermeneutic circle for the organism's inner world contains [...] a cognitive model of its Umwelt so that we can conclude that the organism is not just a recipient, but a constructor of its own environment.

It is remarkable that, in this conception, the hermeneutic circle of an organism is deemed to depend upon corresponding cognitive modeling. This is in agreement with the basic tenet of cognitive linguistics that knowledge is organized through structures of meaning that stem from the body. To organize knowledge is to construct an environment.

Acknowledgment I would like to thank Professor Irene Mittelberg for the extensive discussions we had on the topics addressed in this paper.

Funding Open Access funding enabled and organized by Projekt DEAL.

Open Access This article is licensed under a Creative Commons Attribution 4.0 International License, which permits use, sharing, adaptation, distribution and reproduction in any medium or format, as long as you give appropriate credit to the original author(s) and the source, provide a link to the Creative Commons licence, and indicate if changes were made. The images or other third party material in this article are included in the article's Creative Commons licence, unless indicated otherwise in a credit line to the material. If material is not included in the article's Creative Commons licence and your intended use is not permitted by statutory regulation or exceeds the permitted use, you will need to obtain permission directly from the copyright holder. To view a copy of this licence, visit http://creativecommons.org/licen ses/by/4.0/.

\section{References}

Alcock, J. (2001). The triumph of sociobiology. Oxford University Press.

Bakhtin, M.M. (2008 [1981]). The dialogic imagination: Four essays. Trans. Emerson, C., Holquist, M. : University of Texas Press.

Barthes, R. (1977). Image Music Text. Fontana Press.

Benedict, R. (1934). Patterns of Culture. Houghton Mifflin Company.

Bernstein, B. (1960). Language and social class. The British Journal of Sociology, 11(3), 271-276.

Brandt, P. A. (2011). What is cognitive semiotics? A new paradigm in the study of meaning. Signata Annales des sémiotiques / Annals of Semiotics, 2, 49-60.

Brandt, P. A. (2020). Cognitive semiotics: Signs, mind and meaning. Bloomsbury.

Campbell, C., Olteanu, A., \& Feil, S. (2021). Peircean anti-psychologism and learning theory. Chinese Semiotic Studies., 17(1), 175-197.

Campbell, C., Olteanu, A., \& Kull, K. (2019). Learning and knowing as semiosis: Extending the conceptual apparatus of semiotics. Sign systems studies, 47(3/4), 352-381. 
Cobley, P. (2010). The cultural implications of biosemiotics. Biosemiotics, 3, 225-244.

Cobley, P. (2016). Cultural implications of biosemiotics. Springer.

Cobley, P., \& Stjernfelt, F. (2015). Scaffolding development and the human condition. Biosemiotics, 8 , 291-304.

Deely, J. N. (2001). Four ages of understanding: The first postmodern survey of philosophy from ancient times to the turn of the twenty-first century. University of Toronto Press.

Eagleton, T. (2000). The idea of culture. Blackwell.

Eliott, N.L. (2019). Observing wildlife in tropical forests. 1: A geosemiotic perspective. Delome.

Geeraerts, D., \& Cuykens, H. (2007). Introducing Cognitive Linguistics. In D. Geeraerts \& H. Cuykens (Eds.), The Oxford handbook of cognitive linguistics (pp. 3-21). Oxford University Press.

Gibson, J. J. (1979). The ecological approach to visual perception. Houghton Mifflin.

Jakobson, R. (1965). Quest for the essence of language. Diogenes, 13(51), 21-37.

Johnson, M. (1987). The Body in the Mind: The Bodily Basis of Meaning, Imagination, and Reason. University of Chicago Press.

Koopman, C. (2009). Pragmatism as Transition: Historicity and Hope in James, Dewey, and Rorty. Columbia University Press.

Kress, G. (2010). Multimodality: A social semiotic approach to contemporary communication. Routledge.

Kress, G., \& van Leeuwen, T. (2001). Multimodal discourse: The modes and media of contemporary communication. Arnold.

van Leeuwen, T. (2005). Introducing social semiotics. Routledge.

Lancaster, L. (2014). The emergence of symbolic principles: The distribution of mind in early sign making. Biosemiotics, 7, 29-47.

Elleström, L. (2018). A medium-centered model of communication. Semiotica, 224, 269-293.

Favareau, D. (2010). Essential readings in biosemiotics: Anthology and commentary. Springer.

Foucault, M. (1981). The order of discourse. In: Young, Robert. Untying the Text: A Poststructuralist Reader, pp. 48-77. London: Roultedge \& Keegan Paul.

Halliday, M. A. K. (1978). Language as social semiotic: The social interpretation of language and meaning. Edward Arnold.

Hoffmeyer, J. (2008). The semiotic body. Biosemiotics, 1(2), 169-190.

Hoffmeyer, J. (2015). Introduction: Semiotic scaffolding. Biosemiotics, 8, 153-158.

Hoffmeyer, J., \& Stjernfelt, F. (2016). The great chain of semiosis. Investigating the steps in the evolution of semiotic competence. Biosemiotics, 9, 7-29.

Labov, W. (1972). Language in the inner city: Studies in black English vernacular. University of Pennsylvania Press.

Lakoff, G. (1987). Women, Fire, and Dangerous Things: What Categories Reveal about the Mind. University of Chicago Press.

Lakoff, G., \& Johnson, M. (1999). Philosophy in the Flesh: The Embodied Mind and its Chal-lenge to Western Thought. Basic Books.

Langacker, R. (1987). Foundations of cognitive grammar. Volume 1: Theoretical prerequisites. Stanford University Press.

Lass, R. (1990). How to do things with junk: Exaptation in language evolution. Journal of Linguistics, 26(1), 79-102.

Lotman, Y. M. (1977). Primary and secondary communication-modeling systems. In D. P. Lucid (Ed.), Soviet Semiotics: An Anthology (pp. 95-98). Johns Hopkins University Press.

Lotman, Y. M. (1990). Universe of the mind: A semiotic theory of culture. I.B. Tauris.

Maran, T. (2020). Ecosemiotics: The study of signs in changing ecologies. Cambridge University Press.

Martinelli, D. (2010). A critical companion to zoosemiotics: People, paths, ideas. Springer.

Merrell, F. (2001). Charles Sanders Peirce's concept of the sign. In P. Cobley (Ed.), The Routledge companion of semiotics and linguistics (pp. 28-39). Routledge.

Mitterlberg, I. (2006). Metaphor and metonymy in language and gesture: Discourse evidence for multimodal models of grammar. Manuscript (March 2005), Doctoral Dissertation. New York: Cornell University.

Mittelberg, I. (2008). Peircean semiotics meets conceptual metaphor: Iconic modes in gestural representations of grammar. In A. Cienki \& C. Müller (Eds.), Metaphor and gesture (pp. 115-154). John Benjamins. 
Mittelberg, I. (2013). The exbodied mind: cognitive-semiotic principles as motivating force in gesture. In: Müller, C., Cienki, A., Fricke, E., Ladewig, S.H., McNeill, D., Teßendorf, S. Body Language - Communication: An international handbook on multimodality in human interaction, Volume 1. : De Gruyter Mouton, 755-784.

Mittelberg, I. (2019). Peirce's universal categories: On their potential for gesture theory and multimodal analysis. Semiotica, 228, 193-222.

Morgan, A. (2014). Representations gone mental. Synthese, 191, 213-244.

Nöth, W. (1998). Ecosemiotics. Sign Systems Studies, 29(1), 71-81.

Olteanu, A. (2019). Schematic enough to be safe from kidnappers: The semiotics of Charles Peirce as transitionalist pragmatism. Journal of Philosophy of Education, 53(4), 788-806.

Olteanu, A. (2020). Translation from a contemporary medi perspective: avoiding culturalism and monolingualism. Social Semiotics. https://doi.org/10.1080/10350330.2020.1714204

Olteanu, A., Campbell, C., \& Feil, S. (2020). Naturalizing models: New perspectives in a Peircean key. Biosemiotics, 13, 179-197.

Pietarinen, A. V., \& Bellucci, F. (2016). The iconic moment: towards a Peircean theory of diagrammatic imagination. In J. Redmond, O. P. Martins, \& Á. N. Fernández (Eds.), Epistemology, knowledge and the impact of interaction (pp. 463-481). Springer.

CP = Peirce, C. S. (1958) The Collected Papers of Charles Sanders Peirce. (Hartshorne, Charles; Weiss, Paul, eds. 1931-1935; Burks, Arthur W., ed. 1958.) Cambridge: Belknap.

EPI = Peirce, C.S. (1992 [1867-1893]). The Essential Peirce: Selected Philosophical Writings: Volumes 1-2. (Eds. Houser N., Kloesel, C.) Bloomington: Indiana University Press.

EPII = Peirce, C.S (1998 [1893-1913]). The Essential Peirce: Selected Philosophical Writings: Volume 2. (Eds. The Peirce Edition Project.) Bloomington: Indiana University Press.

Paolucci, C. (2020). Cognitive semiotics: Integrating signs, minds, meaning and cognition. Springer.

Paivio, A. (1990). Mental representations: A dual coding approach. Oxford University Press.

Piaget, J. (2000 [1954]). The construction of reality in the child. Routledge.

Ramsey, W. M. (2007). Representation reconsidered. Cambridge University Press.

Rodríguez Higuera, C. J. (2018). Productive perils: On metaphor as a theory-building device. Linguistic Frontiers, 1(2), 102-111.

Rodríguez Higuera, C. J. (2019). Everything seems so settled here: The conceivability of post-Peircean biosemiotics. Sign Systems Studies, 47(3/4), 420-435.

Rorty, R. M. (Ed.). (1992 [1967]). The linguistic turn: Essays in philosophical method. University of Chicago Press.

Saussure, Ferdinand de. (1959 [1916]). Course in general linguistics. Eds. Bally, C., Sechehaye, A. Trans. Bakin, W. New York: Philosophical library.

de Saussure, F. (1967 [1916]). Cours de linguistique générale. Payot.

Saussure, Ferdinand de. (1973 [1916]). Cours de linguistique générale. Edition critique preparée par Tullio de Mauro. Eds. Bally, C., Sechehaye, A. Paris: Payot.

Sebeok, T. A. (1965). Animal communication. Science, 147(3661), 1006-1014.

Sebeok, T. A. (1991). A sign is just a sign: Advances in Semiotics. Indiana University Press.

Sebeok, T. A. (2001 [1994]). Signs: An Introduction to Semiotics. University of Tor-onto Press.

Sebeok, T., \& Danesi, M. (2000). The forms of meaning: Modelling systems theory and semiotic analysis. Mouton de Gruyter.

Stjernfelt, F. (2006). The Semiotic Body. A Semiotic Concept of Embodiment? In W. Nöth (Ed.), Semiotic Bodies, Aesthetic Embodiments, and Cyberbodies (pp. 13-48). Kassel University Press.

Stjernfelt, F. (2007). Diagrammatology. An Investigation on the Borderlines of Phenomenol-ogy, Ontology and Semiotics. Dordrecht: Springer.

Stjernfelt, F. (2014). Natural Propositions: The Actuality of Peirce's Doctrine of Dicisigns. Docent Press.

Stjernfelt, F. (2015). Iconicity of logic - and the roots of the "iconicity" concept. In M. K. Hiraga, W. J. Herlofsky, K. Shinohara, \& K. Akita (Eds.), Iconicity: East meets west (pp. 35-53). John Benjamins.

Sonneson, G. (1989). Pictorial concepts: Inquiries into the semiotic heritage and its relevance to the interpretation of the visual world. Lund University Press.

von Uexküll, T., Geigges, W., \& Herrmann, J. M. (1983). Endosemiosis. Semiotica, 96(1-2), 5-51.

von Uexküll, J. (1926). Theoretical biology. Kegan Paul, Trench, Trubner \& Co. Ltd..

Ureña Gómez-Moreno, J. M. (2014). The role of image schemas and superior psychic faculties in zoosemiosis. Biosemiotics, 7, 405-427. 
Ureña Gómez-Moreno, J. M. (2019). The 'mimic' or 'mimetic' Octopus? A cognitive-semiotic study of mimicry and deception in Thaumoctopus Mimicus, 12, 441-467.

Varela, F. J., Thompson, E., \& Rosch, E. (2016 [1991]). The embodied mind: Cognitive science and human experience. The MIT Press.

Viana, A. (2017). The unfolding of language as Hysteron Proteron: Heterochrony and extended connectivity. Biosemiotics, 10, 379-395.

Wilson, E. O. (1998 [1975]). Sociobiology. Harvard University Press.

Zlatev, J. (2015). Cognitive semiotics. In P. P. Trifonas (Ed.), International Handbook of Semiotics (pp. 1043-1067). Springer.

Zlatev, J. (2019). Mimesis theory, learning, polysemiotic communication. In: Peters, M.A. (Ed.) Encyclopedia of Educational Philosophy and Theory. Singapore: Springer, https://doi. org/10.1007/978-981-287-532-7.

Zlatev, J., Sonnesson, G., \& Konderak, P. (Eds.). (2016). Meaning, mind and communication: Explorations in cognitive semiotics. Peter Lang.

Zlatev, J., Wacewicz, S., Zywiczyinski, P., \& Vaan De, W. J. (2017). Multimodal-first or pantomimefirst? Communicating events through pantomime with and without vocalization. Interaction Studies, $18(3), 465-488$.

Publisher's Note Springer Nature remains neutral with regard to jurisdictional claims in published maps and institutional affiliations. 